\title{
Apuntes en torno a los debates y conceptualizaciones del gobierno del Frente Para la Victoria en materia de Defensa
}

Notes on the debates and conceptualizations of the government of the Front for Victory (FPV) in Defense.

PABLO DANIEL ALANIZ

Egresado de la Licenciatura en Ciencia Política de la Universidad Nacional de Río Cuarto. Miembro del Ateneo de Estudios Internacionales de dicha universidad. Correo electrónico: pdalaniz@hotmail.com

\section{Resumen}

El presente trabajo tiene el objetivo de problematizar en torno a las principales perspectivas que se plantearon el gobierno de Néstor Kirchner y Cristina Fernández en relación a la planificación en cuestiones de defensa. Se mencionan algunos de sus principales lineamientos, así como las diferentes etapas y debates de los ejes conceptuales, haciendo hincapié en los objetivos políticos que perseguían con las reformas y la profundización de los principios liminares y los principales lineamientos de los ministros en la cartera durante el periodo de 20032015, etapa que comprende el gobierno del Frente Para La Victoria.

Teniendo en consideración el consenso básico en que se nucleó el proyecto de defensa democrático, sostenemos que la política
Abstract

The present work has the objective of problematizing the main perspectives that the government of Néstor Kirchner and Cristina Fernández had to consider for the planning of defence issues. Some of its main guidelines were mentioned in this paper, as well as the different stages and debates of the conceptual axes, emphasizing the political objectives that had been pursued with the reforms and the deepening of the starting principles and the main guidelines of the ministers portfolio during the 2003-2015 period, a stage that involves the government of the Frente Para La Victoria coalition.

Taking in consideration the basic consensus on which the democratic defence project had been based, we argue that the defence policy that received the most attention was related to the deepening of the 
de defensa que mayor atención recibió, estuvo relacionada con la profundización de los principios liminares en los que se inauguró la política de Defensa de Alfonsín, dado que allí se destaca la definición concreta de las esferas de competencia de "Defensa Nacional y la Seguridad Interior" y el "Gobierno Civil de las Fuerzas Armadas (FFAA)". Por otro lado, la impronta de la gestión de Cristina Fernández tuvo la característica de re-vincular al ministerio de defensa y el sistema de defensa argentino con la producción industrial de índole militar e infraestructural $-y$ en articulación con otras carteras-, el resguardo de los recursos naturales y la integración de las FFAA en el planeamiento estratégico ante eventuales emergencias climáticas.

\section{Palabras clave}

Defensa nacional - kirchnerismo política de defensa - Ministerio de Defensa original principles of Alfonsín's defense policy. In this strategy, the specific definition of the areas of competence of "National Defense and Internal Security" and the "Civil Government over the Armed Forces" stands out.

On the other hand, the Cristina Fernández's administration had the characteristic of linking up again the defence ministry and the argentine defence system with the industrial production of military supplies and infrastructure, and articulating with other areas, such us the safeguard of natural resources and the integration of the Armed Forces in strategic planning in the face of possible climatic emergencies.

Keywords

National defense - kirchnerism defense policy - Ministry of Defense

\section{Defensa Nacional y Seguridad Interna: discusión de modelos y definición política}

Las definiciones políticas referidas a la Defensa Nacional y Seguridad Interna traen aparejado el cierre de una discusión que se plasmó a lo largo de la década de los 90 provocada por el cambio de escenario político internacional y la profunda crisis doctrinal dentro de las instituciones armadas, las cuales venían de un proceso de crisis identitaria irresoluto post derrota en Malvinas. En este marco, el debate al cual puso fin el gobierno de Néstor Kirchner fue el relativo a la intervención de las Fuerzas Armadas (FFAA) en las cuestiones de seguridad interna. 
En correlato con este escenario, irrumpe la acepción de "nuevas amenazas" que, en términos doctrinarios, se ampara en la "incertidumbre estratégica" de las instituciones armadas frente a los nuevos escenarios que se avizoraron a finales del siglo XX con la caída del muro de Berlín y el final de la guerra fría. Este cambio del orden global transformó la lógica de construcción de las hipótesis de defensa a lo largo del mundo debido a que la posibilidad de una guerra masiva que atente contra la seguridad de la población quedó relegada. Ahora, las principales problemáticas que atentaban contra la sociedad provenían de grupos que operaban dentro de la misma como el terrorismo, el narcotráfico, el tráfico de personas, etc.

En este contexto histórico, en donde se inculcó un achicamiento del Estado en relación a las competencias que le correspondían en años anteriores, se abrió la posibilidad de que las FFAA complementaran su formación y modernización atendiendo cuestiones de seguridad interna, a modo de ahorrar costos económicos relevantes debido a el "anacronismo" que suponía un conflicto bélico regional o global (Tello, 2000). Esta perspectiva caló hondo en nuestro país producto de los atentados a la embajada de Israel y la AMIA que dejaron como saldo un centenar de muertos, motivando la posibilidad de que esta discusión se plantee en el seno del gobierno menemista; aunque no se lograron cambios determinantes en el perfil correspondiente a las FFAA.

Siguiendo a Saín, se recalca que esta conceptualización de la defensa estaba promocionada por los diferentes organismos e instituciones pertinentes a la cartera de defensa de Estados Unidos (EEUU), país hegemónico en el sistema regional, desde donde se fomentaba que los cuadros militares y dirigentes políticos latinoamericanos -debido a la inviabilidad o al paso a un plano inferior de los conflictos regionales- modernizaran los sistemas de defensa en pos de poder llevar a cabo acciones subsidiarias en materia de seguridad. Cabe destacar que en nuestro país, la rigidez y claridad de las competencias en materia de defensa establecidas en la ley 23.554 y la crisis existente en las instituciones armadas, evitó que la clase dirigente avance en la utilización de las FFAA en aquella dirección; sobre todo en el desarrollo de los conflictos de diciembre de 2001, en donde el escenario de conflictividad social -que derivó en la renuncia del presidente Fernando de la Rúa y la presidencia temporal de Eduardo Duhaldellevó a que se especule sobre su intervención. Los altos mandos militares se desentendieron completamente de la crisis. (Saín, 2011, págs. 169-179) ${ }^{1}$

En base a lo expuesto, podemos sostener que la discusión sobre los modelos de seguridad y defensa reeditan disputas históricas, debido a que la posibilidad de que las FFAA tengan capacidad de ejercer acciones de inteligencia y/o accionar sobre la sociedad civil en pos de intervenir sobre grupos que operan en su seno, nos remonta a los planteos sobre las competencias que tenían las instituciones armadas en el contexto histórico de la doctrina de la "seguridad

\footnotetext{
${ }^{1}$ El General Olmos, Jefe del II cuerpo del ejército, afirmó en el año 2002 que las FFAA no son una opción de poder, anulando la posibilidad de intervenir en los conflictos políticos como en años anteriores y dando un mensaje de desentendimiento de los conflictos sociales fuera de los marcos legales.
} 
nacional” promovida por el mismo país. En ese sentido, la definición política sobre esta materia acarrea una definición geopolítica debido a la funcionalidad de los intereses con respecto a los planteos de seguridad estratégica, fundamentalmente después de los atentados de las torres gemelas en donde EEUU radicalizó sus planteos sobre la cartera de defensa.

Cabe destacar que pese a que la reglamentación de la ley en defensa $\left(\mathrm{N}^{\circ}\right.$ 23.554) a través del decreto 727/2006 tardó en concretarse aproximadamente tres años desde la llegada de Néstor Kirchner al gobierno (si bien la ley es del año 1988), las señales políticas de revisión de la cartera de defensa fueron inmediatas. En ese sentido, podemos visualizar que las intervenciones en su discurso de asunción ante la asamblea legislativa el 25 de mayo de 2003, iban enmarcadas en retomar una fuerte política de Derechos Humanos (DDHH), sobre todo en lo que refiere a los crímenes de lesa humanidad (profundizaremos ello en el presente capítulo) en la que necesariamente tendría que afrontar la reforma de las FFAA en su conjunto debido a los vestigios autoritarios que persistían en éstas:

"En materia de defensa, actuaremos con un concepto integral de la defensa nacional, integrando la contribución de la acción de nuestras fuerzas armadas en pro del desarrollo, trabajando para su modernización e impulsando la investigación científico tecnológico en coordinación con otros organismos gubernamentales, para que, sin apartarse de su actividad principal puedan contribuir al bienestar general de la población...Queremos a nuestras fuerzas armadas altamente profesionalizadas, prestigiadas por el cumplimiento del rol que la Constitución les confiere y por sobre todas las cosas, comprometidas con el futuro y no con el pasado." (Kirchner N. 2003)

Por consiguiente, la necesidad de redefinir competencias institucionales de los organismos referidos al ámbito de defensa y seguridad iban en correlato con la posibilidad de que exista una injerencia de las instituciones armadas en la sociedad civil, por lo cual se optó por un modelo de defensa ajeno al propuesto en la década de los 90. Esta apreciación se refuerza, a lo largo del discurso, con la vinculación de la seguridad como una problemática en la que la policía y la sociedad debían intervenir en carácter de "prevención" y entendiendo que los hechos de inseguridad estaban vinculados a un sistema que había desamparado a las mayorías. Finalmente, en su alusión nunca hizo mención de la militarización de problemáticas referidas a la sociedad civil y a la lucha contra grupos terroristas.

La elaboración del documento de la "Defensa Nacional en la agenda democrática”, marcaba un antecedente importante a la hora de graficar lo que serían los ejes de la política en esta materia, debido a que abría el debate a civiles especialistas, cuadros militares y miembros de instituciones para discutir la defensa. En este documento se detallaron los ejes de los intereses vitales y estratégicos para las instituciones armadas, y las misiones que le concernían a éstas, aunque cabe destacar que en el documento no detallaron a las "nuevas 
amenazas" como misiones para planificar la defensa, por lo que los principales objetivos de las FFAA se limitaban a sostener la integridad territorial.

Por otro lado, es apreciable que en los foros internacionales referidos a la temática de seguridad, en donde se destaca la declaración de Guayaquil y la Conferencia Especial sobre seguridad dependiente de la Organización de los Estados Americanos (OEA) en el año del 2003, se sostiene a las "nuevas amenazas" como una problemática elemental dentro de la "seguridad hemisférica"; y se reconoce la cooperación regional como mecanismo para luchar contra ella otorgando autonomía normativa respecto a las estrategias para intervenir en los conflictos (OEA, 2003, págs. 2-6). Esto evidencia que a nivel internacional el gobierno entrante reconocía a las "nuevas amenazas" como uno de los tantos flagelos en el escenario global, pero sostenía una posición soberana a la hora de decidir las estrategias para abordarla.

En correlato con lo previamente planteado y en paralelo con la apertura del control civil sobre las instituciones armadas, la definición de esferas claras entre defensa nacional y seguridad interna se concretó con la mencionada reglamentación de la ley 23.554 por el decreto $727 / 2006$, iniciando la impronta que se le asignó a la defensa y al planeamiento estratégico durante el gobierno del Frente Para la Victoria.

\section{Conducción civil de las instituciones de defensa}

La necesidad de reconstituir unas FFAA acorde a la institucionalidad democrática ha sido el objetivo político más visible de la gestión kirchnerista en esta materia y se dio en paralelo a la constitución de una fuerte política de $\mathrm{DDHH}$, vinculada al reconocimiento del terrorismo de Estado y la apertura de los juicios a los crímenes de lesa humanidad. Además, la necesidad de reconstituir una nueva estructura de mando venia de la mano con la construcción de un nuevo éthos dentro de las FFAA acorde a los tiempos políticos del país. En este aspecto una de las aristas visibles fue la de erradicar la posibilidad de que las instituciones militares retomasen un rol protagónico en la política nacional, sumado la desmonopolización del planeamiento militar por parte de las instituciones militares.

Por consiguiente, el perfil que Néstor Kirchner le imprimió a su mandato fue la asunción del rol que le confiere la constitución nacional de comandante en jefe de las FFAA, gesto evidente en el descabezamiento de las cúpulas militares y en la orden de bajar los cuadros de Videla y Galtieri en la Ex ESMA (Escuela de Mecánica de la Armada). Siguiendo a Saín, este primer hecho significó uno de los grandes avances para desactivar el pacto radical-peronista que le otorgó cierta autonomía a las fuerzas durante la década de los $90^{2}$, además de la decisión política del cambio de cúpulas y el pase a retiro del general Brizone (Saín, 2011, págs. 191-200)

\footnotetext{
${ }^{2}$ Este pacto se sostuvo durante el gobierno de Eduardo Duhalde debido a la cercanía que tenía éste con las cúpulas militares proclives a que la corte ampare las leyes de "punto final" y "obediencia debida".
} 
Por otro lado, este aspecto era necesario para iniciar la mencionada política de DDHH y conformar una alianza estratégica con los organismos defensores de los mismos en pos de constituir una legitimidad social, que el gobierno no poseía entonces ${ }^{3}$. Asimismo, constituyó una de las primeras victorias dentro de la incipiente interna peronista que se profundizaría en el futuro con el denominado duhaldismo, por la conducción del Partido Justicialista (PJ).

En correlato con lo previamente planteado, Néstor Kirchner proclama el decreto 420/03 que anula el 1581/01, permitiendo la extradición de personas que habían cometido crímenes de lesa humanidad durante la última dictadura militar, algo evitado por el gobierno de De la Rúa). Asimismo, en agosto de 2003 el congreso con apoyo del gobierno aprueba las leyes 25.778 y 25.779 en donde la primera, le otorgaba jerarquía constitucional a la "Convención sobre la imprescriptibilidad de los crímenes de guerra y de los crímenes de lesa humanidad" de 1968 de la Asamblea General de las Naciones Unidas (aprobada por nuestro país en la 24.584) y, la segunda, anulaba la ley 23.492 de punto final y 23.521 de obediencia debida.

La necesidad de iniciar la política de DDHH como reconstitución histórica a las víctimas del terrorismo de Estado, en la lucha contra la impunidad del mismo ${ }^{4}$, dio cabida a una serie de reformas en el ámbito de la defensa que habían sido repelidas, como expresamos en el capítulo 1, por los actores vinculados a la represión durante el gobierno de Raúl Alfonsín estancando cualquier decisión política relevante en esta materia durante el periodo democrático. Siguiendo la línea de Diamint, Argentina como muchos países latinoamericanos, había optado en la transición democrática antes por la "gobernabilidad que por la democracia"; en ese marco los gobernantes evitaron hacer cualquier reforma que pudiese generar eventualmente algún tipo de confrontación con las instituciones militares. Por consiguiente esta decisión política de iniciar la apertura a juicios sobre los delitos de lesa humanidad en la última dictadura militar, la correspondiente depuración de los actores vinculados a la misma y el enjuiciamiento de las cúpulas militares del último gobierno de facto, se encontraba circunscripta a la opción por "la democracia" y por ende se abría la posibilidad de trastocar la impronta de las instituciones armadas en la que persistían vestigios autoritarios, que en anteriores años se vio negada. (Diamint, 2010, pág. 230)

Por otra parte, como mencionamos en el presente capitulo, la elaboración del documento de la defensa nacional en la agenda democrática, establecía una ruptura con el paradigma anterior de defensa en donde los militares poseían un monopolio en el planeamiento logístico de la misma. Este documento es el puntapié inicial para las futuras reformas que se darán en esta materia y en ese sentido Néstor Kirchner se pronunció al respecto:

\footnotetext{
${ }^{3}$ Es menester recordar que Néstor Kirchner asume con el $22 \%$ de los votos después que Carlos Menem se negara a enfrentarse a un ballotage. Por ende la construcción de legitimidad fue una de las cuestiones más relevantes en los primeros años de gestión, entre otras cosas.

${ }^{4}$ En ocasión del discurso de Néstor Kirchner del 24 de marzo del año 2004 en la Ex ESMA donde se proclamó la creación del museo de la memoria.
} 
"La defensa no es solo una obligación de quienes lucen uniforme; debemos ubicarnos todos los argentinos en esta circunstancia. La democracia debe poner en su agenda la cuestión de la defensa nacional y no puede hacerlo sin la participación de todos los actores, de todas las ideas, de todas las escuelas de pensamiento, terminando con la idea de una defensa cerrada a unos pocos o en la cabeza de unos pocos iluminados... Para nosotros, este tema es de real importancia que nuestras Fuerzas Armadas y la sociedad deben asumir con total responsabilidad. Tuvimos en nuestra historia reciente, por no haber tenido los marcos del dialogo democrático y del disenso necesario, doctrinas como la doctrina de la seguridad nacional que causaron un tremendo daño a la sociedad argentina."(Ministerio de Defensa, 2003)

Por consiguiente, esto evidencia la apertura de la discusión académica de en pos de poner en la agenda de la sociedad a la "Defensa Nacional", la cual había sido un asunto ajeno a numerosos actores dado el desinterés civil por la política, la poca relevancia de la temática en relación a los problemas estructurales de los países en vía de desarrollo (inflación, pobreza, desempleo, etc.) y el rechazo a las instituciones militares producto de su accionar en tiempos anteriores.

Es menester remarcar cómo se destaca en el documento la reconceptualización de los objetivos y las misiones específicas que tienen las FFAA como instrumento de defensa de la nación, en donde la protección de los DDHH se vuelve una de ellas, así como la reafirmación de la estructura orgánica de la misma amparada en la ley 23.554. En esa ley también se destacan las atribuciones del Ministerio de Defensa en el ordenamiento de las cuestiones referidas a protección de los intereses vitales y estratégicos del país, en carácter de articulador con la $\operatorname{CODENA}^{5}$ y el $\mathrm{EMCO}^{6}$, debido al rol que se le atribuye como "conductor de la defensa" y ordenador del mismo.

En base a lo previamente nombrado, el Ministerio de Defensa en nuestro país adquiere un rol preponderante como el organismo que debe asegurar el control civil de las instituciones armadas, por su centralidad en todo lo que respecta a la misma. Cabe destacar que posee como factor determinante la organización del presupuesto, un elemento coercitivo notable (debido a la constricción de éste en países en vía de desarrollo) a la hora de su ejecución, control, y relevamiento de las diferentes áreas, haciendo valer las posibilidades del Ministerio como único vehículo por el cual los gobiernos latinoamericanos ${ }^{7}$ “pueden ejercer el mandato popular otorgado por la sociedad". (Diamint, 2010, págs. 228-229).

\footnotetext{
${ }^{5}$ Consejo de Defensa Nacional.

${ }^{6}$ Estado Mayor Conjunto de las Fuerzas Armadas.

7 La autora hace hincapié en el estudio de los ministerios de defensa en donde visualiza que existen aspectos comunes en el proceso de control de las Fuerzas Armadas por parte de los gobiernos en los países latinoamericanos en general.
} 
Por lo tanto, el fortalecimiento del Ministerio de Defensa se basaba en la visualización de un estado de situación, en donde existía un desfasaje histórico en las relaciones civiles y militares, en donde el ministerio se había visto imposibilitado en el cumplimiento de los roles que se les ha habían asignado, dentro de un marco democrático.

\begin{abstract}
“los Ministerios fueron creados para alcanzar cuatro propósitos principales: estructurar las relaciones de poder entre los civiles democráticamente elegidos y las fuerzas armadas, definir y distribuir las responsabilidades entre civiles y oficiales militares, maximizar la eficacia del empleo de las fuerzas armadas (ofrecer seguridad y defensa a la nación), y maximizar la eficiencia en el uso de los recursos. En ese sentido, sus competencias centrales se corresponden con las áreas de personal, presupuesto, adquisiciones y definición de roles y funciones de las fuerzas. Pero además, para esto, se necesita personal civil profesional, con cierta perspectiva de estabilidad en sus cargos, incluidos en puestos claves; al respecto, su investigación evidencia la existencia del problema por el que atraviesan la mayoría de las democracias jóvenes: la ausencia de personal civil de carrera, con estabilidad, como también la politización de la mayoría de los puestos de gobierno; por otra parte, si el Ministerio de Defensa tiene como personal a oficiales en actividad o en retiro, las posibilidades e incentivos para incluir a civiles en la estructura burocrática son menores”. (Rutz, 2014, pág. 3)
\end{abstract}

También deja entrever que este fortalecimiento administrativo del Ministerio de Defensa en el mediano plazo es viable para asegurar cambios loables en esta materia, debido a la debilidad institucional que posee el parlamento en su correspondiente comisión de Defensa, donde no existe el oportuno canal de diálogo que se supone debería tener como representante cabal de la sociedad civil, el ejecutivo y las instituciones armadas, y es inconducente a la hora de poder establecer la respectiva auditoria sobre esta materia específica. Este aspecto se grafica en la pormenorización que posee la comisión bicameral que se encuentra relacionada al control del Ministerio de Defensa, la debilidad que poseen los partidos que no se encuentran en la conducción política a la hora de establecer un correcto seguimiento en esta área y al hiperpresidencialismo que caracteriza a los sistemas políticos latinoamericanos.

En correlato con ello, la construcción de un Ministerio de Defensa que sea el articulador de la política militar y la política defensa, ejecutor del mandato popular por medio del comandante en jefe de las FFAA, permitió abrir canales de discusión de los ejes lineales y estratégicos de la cartera; el objetivo de Néstor Kirchner era la consolidación de una clara cadena de mando que permitiese un intercambio entre civiles y militares, pero que la hegemonía esté sujeta a los primeros, en pos de que las decisiones últimas dadas por los civiles se encuentren legitimadas. 8 La necesidad de clarificar y consolidar esta relación entre el

\footnotetext{
${ }^{8}$ Esta situación se grafica normativamente en el Decreto $N^{\circ} 727 / 2006$, en donde se exponen los alcances normativos y los roles que le competen a todos los organismos que están vinculados a la "Defensa Nacional".
} 
Perspectivas Revista de Ciencias Sociales - ISSN 2525-1112 |Año 2 No. 4 Julio-Diciembre 2017, pp. 125-140

Ministerio y las FFAA era imperativa para establecer una nueva concordia con la sociedad y posibilitar que los posteriores cambios que se dan en la impronta del gobierno de Cristina Fernández en lo que respecta a potestades y articulaciones con otras instituciones adquieran una legitimidad y un hábito creciente.

Por lo tanto, el Presidente Néstor Kirchner hace referencia en su discurso de asunción a que en su gestión iba a implementarse un "perfil profesionalizado" de las FFAA. Para ello, el restablecimiento previamente mencionado de las esferas de competencia entre "defensa nacional y seguridad interna" iban atadas indefectiblemente a la construcción de unas instituciones armadas en donde exista una correspondiente interdependencia entre civiles y militares en los desafíos futuros, sumado a la necesidad de servir a la política de Estado. Por consiguiente, uno de los puntos elementales de la gestión era imprimir un nuevo éthos profesional, debido a la crisis orgánica e identitaria que existía dentro de las Fuerzas. En ese sentido, el presidente se expresa en uno de sus discursos a las tropas haciendo énfasis en este punto:

"El Gobierno que encabezo ha definido de manera meridiana la orientación de la defensa en el marco constitucional de la vigencia de los derechos humanos y del derecho internacional humanitario. La revisión crítica del pasado está siendo acompañada por la necesaria capacitación de los cuadros castrenses en esta materia. En el día de hoy comienza en el Ministerio de Defensa un curso dirigido a jefes, oficiales y suboficiales, que durante una semana trabajarán en el más alto nivel para que la tarea futura nos permita superar definitivamente los oprobios del pasado. Aspiramos a que como ciudadanos soldados los hombres del Ejército participen de su tarea específica, la de profesionales de la guerra en el marco de la estrategia defensiva que adoptamos. Queremos Fuerzas Armadas prestigiadas por el cumplimiento de su rol y comprometidas con el futuro de la Nación... Quiero que quede claro que como presidente de la Nación Argentina no tengo miedo ni les tengo miedo, que queremos el Ejército de San Martín, Belgrano, Mosconi y Savio, y no de aquellos que asesinaron a sus propios hermanos, que fue el de Videla, Galtieri, Viola y Bignone. Hay un nuevo país, necesitamos soldados comprometidos con el destino de la patria, y como presidente de la Nación Argentina vengo a reivindicar un Ejército nacional, comprometido con el país y alejado definitivamente del terrorismo de Estado... Señores oficiales y suboficiales, les pido fuertemente ese concepto y esa filosofía que definitivamente nos incorpore a la construcción de la patria que los argentinos necesitamos. Muchísimas gracias." (Kirchner N. 2006)

Cabe destacar que se asume que esta impronta que se le deseaba imprimir al cuadro militar iba en contramano al desguace que había significado para las FFAA la década de gobierno menemista: las reformas de índole administrativas, el pase a un sistema voluntario de reclutamiento, la creciente anti-militarización ideológica de la clase política (por el desinterés sobre la Defensa Nacional) y la pérdida de prestigio de la profesión militar por parte de la sociedad civil, habían culminado en una crisis del éthos militar en donde imperó 
el individualismo del soldado por sobre el conjunto del cuerpo. (Acuña \& Runza, 2006, págs. 55-62)

Por consiguiente, la necesidad de reconstituir una nueva mentalidad del ejercito inspirada en el "pensamiento Sanmartiniano e independentista" va acorde a darle a éste una formación de índole democrática y nacional, en donde no exista en la cosmovisión del mismo, la posibilidad de intervenir en cuestiones que no le competen. Para asegurar esto debe existir un acompañamiento o una perspectiva en común de la comunidad nacional en lo que respecta a facultades de la misión militar y una asunción de la conducción civil de la defensa y la seguridad por parte de la clase dirigente. (Rutz, 2014, págs. 9-10).

En torno a este último, podemos establecer ciertos puentes con respecto al planteo de Castaldi y Eissa (Castaldi \& Eissa, 2014, págs. 11-13) en relación al concepto de "ciudadano militar" en donde esbozan que este cambio de perfil es acorde a los tiempos políticos en los cuales se sitúa la post guerra fría, y clarifica el rol que posee en la sociedad el militar como parte de la misma, por ende, sujeto a la conducción civil y el gobierno que representa a ésta. Para profundizar sobre ello, los autores hacen hincapié en el proceso al que fueron sujetas las fuerzas Armadas Alemanas después de la 2da guerra mundial, en donde tuvieron que hacer énfasis en el concepto de "Innere Führung", en donde se permite entrever que existe una fuerte impronta en la educación ética de los uniformados, donde el principal valor que se intenta inculcar es el "respeto a la dignidad humana como intangible e invulnerable", en ese sentido se suplanta la "obediencia debida" por la "obediencia consiente". Finalmente expresan que el modelo de ciudadano militar expuesto por este país se resume en tres criterios elementales, estos son: “a) Un soldado operativo, es decir, preparado para actuar, lo cual supone que debe ser capaz de actuar y tener predisposición para hacerlo. b) Un ciudadano responsable. c) Una personalidad libre." (Gastaldi \& Eissa, 2014; pág 12)

Por último, en lo que respecta uno de los aspectos normativos más relevantes que se encuentran íntimamente ligados al espíritu del principio "control político" del proceso político, continuado por Cristina Fernández de Kirchner y la Ministra Nilda Garré, puede mencionarse: la aprobación en el año 2008 de una reforma de carácter integral para las FFAA en su relación con la justicia; el 6 de Agosto de ese año el Congreso Nacional, sancionó la ley 26.394, en donde se derogó el antiguo Código de Justicia Militar (como las resoluciones de carácter interno que lo reglamentaban), y se modificó una parte del Código Penal y el Código Penal Procesal en pos de introducir a ellos los "delitos militares", además de eliminarse el fuero militar para juzgar delitos cometidos dentro de las FFAA, siendo éstos esfera de la justicia federal. Cabe destacar que,

9 "Este concepto abreva en las siguientes tradiciones alemanas: a) las reformas realizadas en el ejército prusiano como consecuencia de las Guerras Napoleónicas (1792-1815) y que tienen, como referencia a pensadores como Carl von Clausewitz, Gerhard von Scharnhorst y August von Gneisenau; la resistencia alemana al totalitarismo nazi; y el documento llamado Memoria de Himmerode de 1950, que buscó sentar los fundamentos de un nuevo soldado y de los valores que guían su comportamiento en la sociedad"

(Andress, 1997). 
en esa ley, también se aprobaron: Procedimiento Penal Militar para Tiempo de Guerra y Otros Conflictos Armados, las Instrucciones para la Población Civil en Tiempo de Guerra y Otros Conflictos Armados, Código de Disciplina de las Fuerzas Armadas, Servicio de Justicia Conjunto de las Fuerzas Armadas.

Estas normativas venían a estructurar el accionar de las FFAA en lo que respecta a su conducta consecuente a la legalidad y las sanciones en caso de incumplirlas. Asimismo, es menester remarcar el cambio en la cultura social y política que significa el hecho de que se juzgue a los militares como ciudadanos. Es decir, en caso de incumplir los deberes que le competen o faltar a los mismos en su accionar se le juzga en una cámara federal. Asi, se deja entrever el rol que posee la educación como un aspecto necesario para cambiar el perfil de soldado, profundizando este aspecto con la promulgación del Decreto $N^{\circ}$ 1714/2009 "Directiva de Política de Defensa Nacional", poniendo de manifiesto que la educación y la formación curricular serian uno de los aspectos más relevantes.

Desarrollo Industrial, asistencia humanitaria y recursos naturales en el marco de la Defensa Nacional.

El proyecto de defensa impulsado por el Kirchnerismo durante su primera gestión tenía la necesidad de generar las condiciones institucionales en pos de abrir la puerta a un desarrollo integral de la cartera, acorde al contexto global y regional. Es por ello que este apartado tiene la necesidad de indagar sobre aspectos elementales de dicha política debido a la importancia que adquieren durante la gestión de Cristina Fernández de Kirchner, en donde se puede entrever que los objetivos prioritarios eran el de impulsar la rearticulación del aparato productivo de la Defensa nacional -desguazado y privatizado parcialmente en el gobierno menemista- con objetivos integrales en todos los niveles del Estado, la coordinación de la asistencia humanitaria y la defensa de los recursos naturales

Con respecto al desarrollo industrial, podemos decir que este aspecto es relevante en lo discursivo durante los encuentros de la cena de camaradería donde el Jefe de Estado, en su mandato como Comandante en Jefe de las FFAA, hace un repaso sobre los principales ejes de la gestión y los lineamientos a seguir por parte de la misma. Podemos observar que, durante la gestión de Cristina Fernández, existe una revalorización del aparato industrial, de la necesidad estratégica de éste y de los profesionales civiles involucrados en el mismo. Como síntesis de ello expone en la cena de camaradería del año 2013:

“...defensa integral que pasa por el desarrollo industrial, por agregar valor, por participar activamente en el desarrollo de la industria de defensa nacional, de manera tal que podamos producir, mediante lo que tenemos en materia de ciencia y tecnología, desde radares hasta armamento, hasta vagones para trenes, hasta volver a ser ferrocarriles, todo, todo hace al concepto de defensa, de defensa de un modelo que ha permitido un crecimiento y una inclusión social sin precedentes." (Fernández C. 2014) 
También se deja entrever la integralidad de la visualización de la labor del Ministerio de Defensa en lo que respecta labores de articulación con otros ministerios como el "del Interior y Transporte", Fabricaciones Militares y el Instituto Nacional Geográfico en los acuerdos de desarrollo de vagones para la reapertura del sistema de trenes en nuestro país

La recuperación de las empresas relacionadas con la capacidad industrial de las FFAA, el pase correspondiente de éstas a las dependencias del Ministerio de Defensa, y la creación o fortalecimiento de empresas estratégicas en materia satelital con inversión estatal, en las que se destacan como estandartes de este proceso: INVAP ${ }^{10}$, ARSAT, TANDANOR, FADEA, entre otros, sumado a la incentivación de la investigación por medio del CONICET en pos de generar patentes y nuevos conocimientos; manifestaba que existía una intención política en materia de generar desarrollo de conocimientos estratégicos para poseer mayores márgenes de maniobra y autonomía en este sector, sumado a una revalorización -por motivos del proyecto económico- de lo que significa la industria como ahorrador de divisas. En este sentido, se favorecía la balanza de pagos debido a que las diversas incorporaciones y mantenimientos de los equipos en esta área demandan sumas económicas importantes para un Estado en vía de desarrollo y producen una dependencia tecnológica relevante. (Fernández C. 2011)

Además, podemos destacar la importancia de la revalorización de la industria militar nacional al compararla con la relevancia que había adquirido en otros momentos históricos en donde Argentina estaba situada en la vanguardia militar y doctrinal.

Por lo tanto, mi visión acerca de ese rol que debe desempeñar la Argentina en la región no está vinculada a una nación de superioridad sobre los otros, sino al contrario, una nación de nuestra competencia, de nuestras capacidades, de nuestra historia, de ser realmente un gran país. Está en la génesis, hemos sido capaces de construir los primeros aviones, hemos sido capaces de ser punta de lanza en materia de industria naval, en materia de marina mercante, en materia nuclear, aún lo seguimos siendo en algunos aspectos. (Cristina Fernández, 2009)

En este sentido, también adquiere una relevancia de carácter simbólico que se imprime a la nueva institucionalidad de las FFAA, en donde no solamente estén organizadas para defender la integridad del territorio argentino al servicio de la defensa de la democracia y la constitución, sino con el compromiso de trabajar junto a los civiles especializados en la temática - en la innovación del instrumento militar en lo que respecta planificación, infraestructura y equipamiento, entre otros, para lograr autonomía y soberanía.

Con respecto a las FFAA y su accionar de asistencia humanitaria, la Jefa de Estado hace un llamamiento en el último periodo de su gestión a una nueva

${ }^{10}$ Cabe destacar, que esta empresa es una sociedad del Estado rionegrina, creada en 1976 en articulación con el gobierno de dicha provincia y la Comisión Nacional de Energía Atómica. 
compenetración entre la sociedad civil y el ejército en esta materia. Al respecto, considera como prioritaria esta misión del ejército, por consiguiente, el Ministerio de Defensa tiene la necesidad de reestructurarse para articular con los organismos civiles competentes para lograr una efectiva coordinación y despliegue que posibilite solucionar los problemas urgentes que dejan los siniestros de esta índole. Esta perspectiva se incorporó de forma más acentuada producto de la catástrofe en La Plata en el año 2012 que dejó centenares de víctimas y miles de afectados.

“...que es una buena oportunidad para reflexionar a partir de lo que ha sido la reformulación o la reestructuración del ministerio de Defensa, de las exigencias y los desafíos, que nos plantea al Estado argentino y a sus Fuerzas Armadas, como parte de ese Estado, esta nueva etapa: la creación de una Secretaría de articulación militar para la emergencia, que algunos definen como una tarea auxiliar, pero decíamos, el otro día, con el ministerio de Defensa, la solidaridad con el prójimo y con la comunidad jamás puede ser una tarea auxiliar de ningún argentino y mucho menos de sus Fuerzas Armadas."(Fernández C. 2013)

La conceptualización de la defensa nacional que anteriormente exponíamos, evidencia la perspectiva de un ejército con la capacidad de despliegue para cualquier evento que afecte a la población. La importancia que adquiere el hecho de la institucionalización de este rol, demuestra que la articulación con otros organismos civiles es menester para lograr una óptima planificación y organización de aquello que no está previsto, por consiguiente, se puede entrever que la preponderancia que adquieren las FFAA en la asistencia y solución de estos problemas, posibilita que se amplíe el marco de la relación entre los civiles y militares, en este caso por un motivo especifico.

Con respecto a la impronta que adquiere la defensa de los recursos naturales podemos decir que este punto es un aspecto notable en la funcionalidad de las FFAA en cuanto a los intereses vitales de la nación. La relevancia como eje se debe a grandes rasgos, a una evidente importancia de éstos en el marco de una disputa geopolítica que estaba llevando a cabo el gobierno del Frente Para la Victoria en concomitancia con los países de la región en relación a los agentes externos como las empresas multinacionales, la Unión Europea (UE), EEUU, entre otros:

Quiero decirles especialmente a todos y a todas quienes integran las Fuerzas Armadas, lo comentaba ayer en esta nueva reconfiguración del mundo que se está produciendo, me acuerdo la primera charla que di aquí, la primera reflexión que hice frente a ustedes en la primera Cena de Camaradería, si mal no recuerdo un 6 de julio de 2007, en mi primera ocasión como Presidenta de la República y como Comandante en Jefe de las Fuerzas Armadas, hablar de un mundo que iba a necesitar defender, como lo dije el otro día, sus recursos naturales. Ahora, no solamente vamos a necesitar defender nuestros recursos naturales, sino reafirmar y profundizar lo que 
hemos logrado en estos años en materia de reindustrializar y rearmar el país para no ser solamente un productor de materias primas.

No conozco ningún gran ejército, no conozco ninguna gran armada, no conozco ninguna gran aviación que solamente sean custodios de países donde lo único que se produce son materias primas. La grandeza de las Fuerzas Armadas está directamente vinculada al poder y a la grandeza de la Nación. (Fernández C. 2014)

Cristina Fernández tenía como objetivo restructurar las FFAA para ponerlas acorde con una política integral de desarrollo nacional y enaltecimiento de la soberanía política -eje de la política exterior- en el marco de la integración territorial. Es menester recordar que esto adquirió una notable relevancia debido al descubrimiento de "Vaca Muerta" por ende la revalorización de la política energética - en ese marco la estatización del 51\% de las acciones de YPF- y la disputa con los fondos buitres por la reestructuración de la deuda, hechos que signaron la agenda de la política macroeconómica en pos de defender las líneas estratégicas de un proyecto económico y social.

\section{A modo de cierre}

Con respecto a los principales planteos relacionados al proyecto de defensa del gobierno del Frente Para la Victoria podemos encontrar que, si bien se pueden enmarcar distintos momentos dentro de la complejidad del proceso político del kirchnerismo, en materia de defensa se ha trabajado con ciertos lineamientos en común circunscriptos al proyecto de defensa democrático, profundizando en ciertas aristas.

Por un lado, podemos establecer que la situación inaugural en la que se encontró el gobierno de Néstor Kirchner afectó de forma diametral al Ministerio de Defensa, en donde estableció las principales reformas que apuntalaron los ejes que enmarcarían la política del mismo en toda la gestión del Frente para la Victoria; haciendo hincapié en el rol estratégico que poseen las FFAA, delimitando las esferas de competencia de éstas y, posibilitando, por añadidura, el debate sobre el planeamiento de las instituciones de defensa. Ese aspecto es menester enmarcarlo como un hecho que no se encuentra aislado a ninguno de los puntos liminares del documento "Defensa Nacional en la agenda democrática", debido a que la construcción de la "conducción civil de las FFAA" se encuadraba en un periodo complejo caracterizado por la apertura de los juicios por delitos de lesa humanidad y las decisiones políticas circunscriptas a la construcción de nuevo "éthos" militar contenido en el sistema democrático, bajo supuestos de trabajo soberanos, que apuntaran a lograr una estructura orgánica de esta área estratégica.

En esa línea, podemos decir que la perspectiva en la que se encuadró el gobierno de Néstor Kirchner fue la búsqueda de una "reconciliación" por parte de la sociedad para con las instituciones de defensa, sumado a una ponderación de las empresas vinculadas a esta área estratégica del Estado.

La primera gestión fue un reacomodamiento de determinados actores y una transformación institucional en cuanto a los roles y perspectivas que poseía 
el Estado argentino en materia de defensa retomando nociones elementales del proyecto de defensa democrático, sobre todo de Alfonsín.

Por otro lado, la gestión de Cristina Fernández supuso una clara continuidad en la profundización de la estructura orgánica del Ministerio de Defensa sobre los ejes liminares que manifestó Néstor Kirchner; en ese aspecto, el rol en el que se quiso situar a la labor de esta área se encontraba contemplada en un proyecto nacional, ocupando un rol protagónico dentro de la estructura productiva del desarrollo nacional. Por consiguiente, se puede contemplar que la reinstitucionalización de las FFAA en un proceso de profundización del sistema político democrático tenía como fin último reconciliar a éstas con la sociedad civil, situándola en un lugar estratégico para el desarrollo de las capacidades nacionales, la inserción internacional y la política exterior nacional.

Finalmente, en lo que respecta al área de defensa, el gobierno de Cristina Fernández pone en agenda cuestiones de carácter estratégico enmarcadas principalmente en la importancia de los recursos naturales y las dinámicas de los conflictos geopolíticos del siglo XXI por parte de las potencias extraregionales, agravados por el descubrimiento del yacimiento petrolífero "Vaca Muerta". Además, encontramos que a la discursiva en torno al Ministerio de Defensa y la producción de inteligencia estratégica, se suma a una nueva preponderancia en las funciones de éste como organizador y articulador ante eventuales emergencias humanitarias. En ese aspecto, el gobierno de Cristina Fernández apunta a la profundización de las nociones generales que propuso su antecesor, revinculando al Ministerio de defensa y a las instituciones que lo componen a una cosmovisión en defensa de la democracia, la soberanía y a un proyecto político-económico nacional.

Recibido: $20 / 10 / 2017$

Aceptado: 29/11/2017

\section{Referencias Bibliográficas}

Acuña, M., \& Runza, R. (2006): Hacia la Modernizacion del Sistema de Defensa Argentino. Editorial Altamira. Buenos Aires. Argentina

Diamint, R. (2010): La reconstrucción de la seguridad nacional Defensa, democracia y cuestión militar en América Latina. Editorial Prometeo. Buenos Aires. Argentina

Eissa, S. Gastaldi, S. (2014): Cuando las palabras son buenas: la militarización de las Fuerzas Armadas en Defensa Nacional y Pensamiento Estratégico Escuela de la Defensa Nacional (Págs. 4-28) . Ministerio de Defensa. Presidencia de la Nación ISSN 2422-6378

Rutz, G. (2014): Documento de Trabajo N²0 "Abordajes conceptuales del gobierno político de la defensa: una mirada a la Maestría". En linea. Escuela de Defensa Nacional. Ministerio de Defensa. Buenos Aires. Argentina.

Sain, M. (2007): Nuevos Desafios: La defensa Nacional y los asuntos militares en la Argentina Actual. Revista de la defensa nacional №1. En linea. Buenos Aires. Argentina 


\section{Fuentes oficiales}

Decreto No 727/2006 "Reglamentario de la Ley de Defensa Nacional. República Argentina

Decreto $N^{\circ} 1691 / 2006$ "Directiva sobre Organización y funcionamiento de las Fuerzas Armadas". República Argentina Decreto $N^{\circ} 1729 / 2007$ "Ciclo de Planeamiento de la Defensa Nacional". República Argentina

Decreto $N^{\circ}$ 1714/2009 "Directiva de Política de Defensa Nacional". República Argentina

Fernández C. (2008): Discurso en la Cena de Camaradería de las Fuerzas Armadas. República Argentina

Fernández C. (2009): Discurso en la Cena de Camaradería de las Fuerzas Armadas. República Argentina

Fernández C. (2010): Discurso en la Cena de Camaradería de las Fuerzas Armadas. República Argentina

Armadas.

Fernández C. (2011): Discurso en la Cena de Camaradería de las Fuerzas

Fernández C. (2012): Discurso en la Cena de Camaradería de las Fuerzas Armadas. República Argentina

Fernández C. (2013): Discurso en la Cena de Camaradería de las Fuerzas Armadas. República Argentina

Fernández C. (2014): Discurso en la Cena de Camaradería de las Fuerzas Armadas. República Argentina

Fernández C. (2015): Discurso en la Cena de Camaradería de las Fuerzas Armadas. República Argentina

Kirchner N. (2003): Discurso de Asunción del Poder Ejecutivo Nacional. República Argentina

Kirchner N. (2003): Discurso en la Cena de Camaradería de las Fuerzas Armadas. República Argentina

Kirchner N. (2006): Discurso Dia del Ejército. Republica Argentina.

Ley Nº 23554 “Defensa Nacional” (1988). República Argentina 